\title{
ARTICLES
}

\section{Novel mutations in Rsk-2, the gene for Coffin-Lowry syndrome (CLS)}

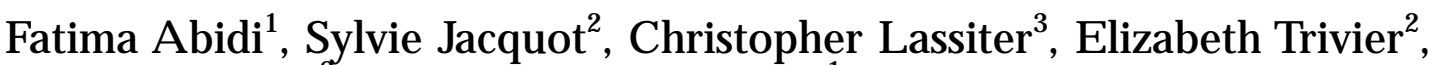 \\ A ndré H anauer ${ }^{2}$ and Charles E Schwartz ${ }^{1}$ \\ ${ }^{1}$ Center for M olecular Studies, JC Self Research Institute for H uman G enetics, G reenwood Genetics Center, \\ G reenwood, SC, USA \\ ${ }^{2}$ Institut de Génétique et de Biologie M oléculaire et Cellulaire, CNRS, INSERM, UL P, Illkirch, France \\ ${ }^{3}$ F urman University, G reenville, SC, USA
}

Coffin-L owry syndrome (CLS) is an X-linked disorder characterized by facial dysmorphism, digit abnormalities and severe psychomotor retardation. CLS had previously been mapped to $X$ p22.2. R ecently, mutations in the ribosomal S6 kinase (Rsk-2) gene were shown to be associated with CLS. We have tested five unrelated individuals with CLS for mutations in nine exons of R sk-2 using Single Strand Conformation Polymorphism (SSCP) analysis. Two patients had the same missense mutation (C340T), which causes an arginine to tryptophan change (R 114W). This mutation falls just outside the $\mathrm{N}$-terminal A TP-binding site in a highly conserved region of the protein and may lead to structural changes since tryptophan has an aromatic side chain whereas arginine is a 5 carbon basic amino acid. The third patient also had a missense mutation (G 2186A) resulting in an arginine to glutamine change ( $R 729 Q)$ ). The fourth patient had a $\mathbf{2}$ bp deletion (AG) of bases $\mathbf{4 5 1}$ and $\mathbf{4 5 2}$. This creates a frameshift that results in a stop codon 25 amino acids downstream, thereby producing a truncated protein. This deletion also falls within the highly conserved amino-catalytic domain of the protein. The fifth patient has a nonsense mutation (C 2065T) which results in a premature stop codon, thereby producing a truncated protein. These mutations further confirm R sk-2 as the gene involved in CLS and may help in understanding the structure and function of the protein.

Keywords: C offin-L owry; R sk-2; SSCP; mental retardation; mutation

\section{Introduction}

Coffin-L owry syndrome is an X-linked disorder characterized as an inherited facio-digital mental retardation syndrome. ${ }^{1}$ Patients diagnosed with CLS exhibit skeletal anomalies with severe psychomotor retardation and their hands appear to be bulbous with tapering

Correspondence: Charles Schwartz, PhD, Center for M olecular Studies, JC Self R esearch Institute, One G regor M endel Circle, Greenwood, SC 29646, U SA. Tel: 864388 1800; Fax: 864388 1707; E-mail: schwartz@ggc.org

R eceived 28 January 1998; revised 6 M ay 1998; accepted 29 M ay 1998 fingers. Other clinical features include patulous lips, larger mouth, anteverted nares, hypertelorism, and prominent frontal region. ${ }^{2}$ A ffected males exhibit severe mental retardation along with characteristic dysmorphic features, whereas in females the phenotypic spectrum covers the entire spectrum including normal appearance or minor dysmorphic features, or the complete syndrome as seen in the male. Linkage studies mapped the CLS locus to Xp22.2, between DXS365 and DXS7161, an interval of approximately $3 \mathrm{cM} \cdot{ }^{3-5} \mathrm{R}$ ecently Trivier et al ${ }^{6}$ showed that mutations in the Rsk-2 gene are associated with CLS. The Rsk-2 gene is a member of the RSK (ribosomal S6 kinase) 
Table 1 Primers and conditions used for genomic amplification of nine R sk-2 exons

\begin{tabular}{|c|c|c|c|}
\hline $\begin{array}{l}\text { Exon } \\
\text { coverage }\end{array}$ & Primer name/sequence & $\begin{array}{l}\text { A nnealing } \\
\text { temp }\end{array}$ & $\begin{array}{l}\text { Product } \\
\text { length }(\mathrm{bp})\end{array}$ \\
\hline nt 326-406 & $\begin{array}{l}\text { VH 236: AGTGGATATTACA ATGTAGCA } \\
\text { VH 237: G G GA GA CG G CTCATA CTTA }\end{array}$ & $55^{\circ} \mathrm{C}$ & 140 \\
\hline nt $407-486$ & $\begin{array}{ll}\text { VG 18: } & \text { TATGAATGACCTA ATGTA A A CC } \\
\text { VG 19: } & \text { CA G GATG CATGTA A ATA G ACT }\end{array}$ & $55^{\circ} \mathrm{C}$ & 190 \\
\hline nt 487-593 & $\begin{array}{ll}\text { VI242: } & \text { ACAGACACA A A A A A A A ATA A AT } \\
\text { V N206: } & \text { ATCATATTACATTGTATTCAACT }\end{array}$ & $50^{\circ} \mathrm{C}$ & 200 \\
\hline nt $1000-1102$ & $\begin{array}{ll}\text { V P47: } & \text { GTATA G A ATG A A A CTTG CTTG } \\
\text { V P126: } & \text { TATTTGTTGTCTTATATTTG GAT }\end{array}$ & $58^{\circ} \mathrm{C}$ & 200 \\
\hline nt 1354-1443 & $\begin{array}{l}\text { V S157: } \\
\text { VHGTATAGTTGATGAG GTTT } \\
\text { VHGACAACTGATTCAAATGA }\end{array}$ & $47^{\circ} \mathrm{C}$ & 170 \\
\hline nt $1766-1841$ & $\begin{array}{l}\text { VH 244: CTA ATTTG CA CTTTTTCTA } \\
\text { VH 245: AATG NTTA G GTG G CTTAGA }\end{array}$ & $54^{\circ} \mathrm{C}$ & 130 \\
\hline nt 1842-1959 & $\begin{array}{l}\text { VH 242: TTTGATAGGAAGTGATACT } \\
\text { VH 243: GAGTACTTTTGAGATTACC }\end{array}$ & $47^{\circ} \mathrm{C}$ & 210 \\
\hline nt 1960-2100 & $\begin{array}{l}\text { WL 166: AAGAGCCTAGAAAAAGC } \\
\text { WL 168: TGGAGGACCTGTGGAAAAC }\end{array}$ & $55^{\circ} \mathrm{C}$ & 200 \\
\hline nt 2100-2259 & $\begin{array}{l}\text { WL 171: TGTGTACGTG TGA CTATCCATT } \\
\text { W 191: GTGTG CTTGCA G G TG TCTCTC }\end{array}$ & $55^{\circ} \mathrm{C}$ & 200 \\
\hline
\end{tabular}

family that consists of growth factor regulated serinethreonine kinases also known as $\mathrm{p} 90^{\text {rsk }}{ }^{7}$. The $\mathrm{R}$ sk-2 CDNA has an open reading frame of $2220 \mathrm{bp}$ and it encodes a protein of 740 amino acids. $^{8}$ In humans, the R SK family is comprised of three isoforms, R sk-1, R sk2 and $\mathrm{R} \mathrm{sk}-3{ }^{7}$ which encode proteins that contain two non-identical kinase catalytic domains. ${ }^{9}$

In their report, Trivier et $\mathrm{al}^{6}$ reported a total of six mutations in the Rsk-2 gene: two missense mutations, one nonsense mutation, two deletions and one insertion. Three of the mutations were in the $\mathrm{N}$-terminal kinase catalytic domain and the other three were in the $C$-terminal kinase catalytic domain. Four of the six mutations resulted in the truncation of the $\mathrm{R} s \mathrm{sk}-2$ protein.

In this study we have tested five unrelated patients with CLS for mutations in the $\mathrm{R} s k-2$ gene. Three patients were familial and two were sporadic cases. We have identified two missense mutations, one nonsense mutation and a 2-base pair deletion. O ne of the missense mutation (C340T) is present in two of the patients. Thus, this study further confirms R sk-2 as the gene involved in CLS.

\section{Materials and Methods}

\section{Patients}

Five males, two Caucasian and three A frican-A merican, carrying the diagnosis of Coffin-L owry (CLS), were available for analysis. Three of the probands had at least a brother who also carried the diagnosis of CLS. The fourth male had a family history of mental retardation in male relatives and his mother and aunt had been assessed as having intellectual impairment. The remaining male had no family history of mental retardation and both parents were reported to have been normal. All of the probands had clinical findings consistent with CLS: large, soft hands with tapering fingers, severe to moderate mental retardation, short stature $(\leq 5$ th centile), weight below the 5th centile, microcephaly, telecanthus or hypertelorism, prominent eyes. The Caucasian probands had large mouths and prominent lower lips. For the A frican-A merican probands this was difficult to determine because of racial background.

\section{PCR Analysis}

Genomic DNA was isolated from lymphocytes using a high salt procedure. ${ }^{10}$ Purified DNA was diluted with TE $(10 \mathrm{mM}$ Tris, $1 \mathrm{mM}$ EDTA $\mathrm{pH} 8.0$ ) to a final concentration of $105 \mu \mathrm{g} / \mathrm{ml}$ and stored at $4^{\circ} \mathrm{C}$. H undred nanograms of genomic DNA were amplified in a total volume of $20 \mu$ l containing $1 X$ $P C R$ reaction buffer $(10 \mathrm{mM}$ Tris, $1.5 \mathrm{mM} \mathrm{M} \mathrm{gCl}, 50 \mathrm{mM} \mathrm{KCl}$, $\mathrm{pH}$ 8.3) with $1 \mu \mathrm{M}$ of each primer, $50 \mu \mathrm{M}$ of dNTPs, 1 unit Taq DNA polymerase (Boehringer $M$ annheim, Indianapolis, IN, U SA ), and $0.1 \mu \mathrm{g}$ of TaqStart antibody (Clontech, Palo A Ito, CA , U SA ). ${ }^{11}$ A mplification was done in a 9600 Thermocyler (Perkin Elmer/C etus, Foster City, CA, U SA ). The information on the PCR primers and their optimal annealing conditions are listed in Table 1. The primers were designed using sequence flanking the particular exon to insure detection of any alteration in the splice junction. A II primers were synthesized and FA M labeled with FlourePrime (Pharmacia B iotech, Piscataway, NJ, U SA ), using an Oligo 1000 DNA synthesizer (B eckman, Fullerton, CA, USA) and were desalted over a NA P10 column (Pharmacia Biotech, Piscataway, NJ, USA). Ten microlitres of the amplified products were checked on a $2 \%$ agarose gel to confirm product amplification. 
Table 2 R sk-2 mutations in 5 CLS patients

\begin{tabular}{|c|c|c|}
\hline Patient & Mutation & Predicted protein sequence* \\
\hline $\begin{array}{l}2598 \text { and } \\
\text { CM S0976 }\end{array}$ & C340T & $\begin{array}{l}\text { GACCGAGTTCGGACAAAA } \\
\text { D R V W T K }\end{array}$ \\
\hline Control & & $\begin{array}{l}\text { GACCGAGTTTGGACA A A } \\
\begin{array}{lll}\mathrm{D} & \mathrm{R}\end{array} \mathrm{V} \mathrm{T} \mathrm{K}\end{array}$ \\
\hline CM S0429 & G 2186A & $\begin{array}{l}\text { ACTCTTGCTCAGCAGAGAGGT } \\
\mathrm{T} \quad \mathrm{L} \quad \mathrm{A} \quad \mathrm{Q} \quad \mathrm{Q} \quad \mathrm{R} \quad \mathrm{G}\end{array}$ \\
\hline Control & & $\begin{array}{l}\text { ACTCTTGCTCAGCGGAGAGGT } \\
T \quad L \quad A \quad Q \quad R \quad R \quad G\end{array}$ \\
\hline 4534 & C2065T & $\begin{array}{l}\text { CTGCCACAATACTAACTAAAC } \\
\mathrm{L} \quad \mathrm{P} Q \mathrm{Q} \text { Y } * \mathrm{~L} N\end{array}$ \\
\hline Control & & $\begin{array}{l}\text { CTGCCACA A TACCAACTAAAC } \\
\text { L P Q Y Q Q L N }\end{array}$ \\
\hline 2423 & 451delA G & 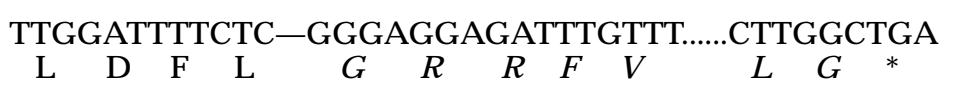 \\
\hline Control & & 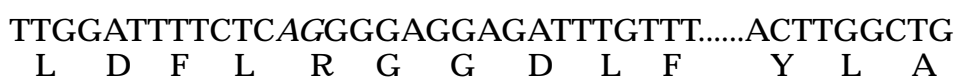 \\
\hline
\end{tabular}

*Predicted amino acid sequence is compared to the normal sequence (listed as control).

\section{SSCP and Sequence Analysis}

A t the time of this study, the exon/intron boundary of only 9 exons had been identified in the R sk-2 gene. SSCP analysis of 7 of the exons was done on the Automated Laser Flourescence (ALF) DNA sequencer (Pharmacia Biotech, Piscataway, NJ, U SA ). Products that showed an altered pattern on the SSCP gel were subcloned. A s a control, a corresponding $P C R$ product amplified from a normal individual was also subcloned. The cloned DNA was sequenced using a Thermo Sequenase fluorescent-labeled primer cycle sequencing kit with 7-deaza-dGTP (A mersham, A rlington Heights, IL, U SA ), FA M -labeled M $13(-40)$ forward and reverse primers (Pharmacia B iotech, Piscataway, NJ, USA ). The sequence was analyzed on the ALF DNA sequencer.

SSCP analysis was done manually for the 2 exons at the $3^{\prime}$ end of the gene. PCR amplification was done in the presence of $1 \mathrm{pmol}(3 \mathrm{mCi})$ of ${ }^{32} \mathrm{P} \mathrm{dCTP}$, after which aliquots of $4 \mu \mathrm{l}$ were denatured for $5 \mathrm{~min}$ at $90^{\circ} \mathrm{C}$ and loaded on a $10 \%$ glycerol, 6\% polyacrylamide gel (acryl-bisacryl, 49:1). Electrophoresis was run at $4 \mathrm{~W}$ for $10-12 \mathrm{hrs}$ in the cold room. The gel was dried and exposed overnight.

\section{Mutation Analysis}

The point mutations C340T and C2065T did not create or remove any restriction site. Therefore a modified primer was designed to create or eliminate a restriction site near the mutation of interest. ${ }^{12}$ For the C340T mutation, primer VH 236A (5'CTTTTATAGTTCGAGACCGAGTC 3'), was designed to introduce a $C$ at position 339 , next to the $C$ to $T$ alteration. This primer creates a $\mathrm{Mspl}$ site in the wild type. Primer VH236A, in combination with $\mathrm{VH} 237$, yields a product of $110 \mathrm{bp}$, which upon digestion with $\mathrm{M}$ spl results in two fragments ( $23 \mathrm{bp}$ and $87 \mathrm{bp}$ ). The fragments were resolved by electrophoresis on a $8 \%$ acrylamide $/ 15 \%$ glycerol mini gel (H oefer, San Francisco, CA, U SA ).

For the C2065T mutation, primer Ex21F (5'GGGACCAACTGCCACAATAT $3^{\prime}$ ) was used to introduce a $T$ at position 2064. This primer creates a Sspl site in the patient. Primer Ex21F, in combination with WL 168, amplified a product of $100 \mathrm{bp}$, which when digested with Sspl gives two fragments ( $83 \mathrm{bp}$ and $17 \mathrm{bp}$ ) in the patient.

The point mutation $\mathrm{G} 2186 \mathrm{~A}$ resulted in the loss of $\mathrm{M} \mathrm{spA} 11$ site in the patient which made it possible to test the mutation in the family and in normal chromosomes.

\section{Results}

Two of the patients (2598 and CM S0976) showed the same abnormal SSCP pattern in the exon defined by nt 326-406 (Table 1). Sequence analysis revealed a C to $T$ mutation (C340T) in both patients, resulting in an arginine to tryptophan change at position 114 (R 114W) in the protein (Table2). The C340T mutation did not create or remove a restriction site. Therefore an alternative primer, $\mathrm{VH} 236 \mathrm{~A}$, was used in combination with VH237 (see Material and Methods) to yield a product of $110 \mathrm{bp}$. Utilization of primer $\mathrm{VH} 236 \mathrm{~A}$ created a novel $\mathrm{M} \mathrm{spl}$ site in the normal D NA sequence. The family of patient 2598 was tested and the $\mathrm{C}$ to $\mathrm{T}$ mutation was shown to segregate with CLS (Figure 1a). A s patients 2598 and CM $S 0976$ are A frican-A merican, $100 \mathrm{X}$ chromosomes from A frican-A merican individuals were analyzed for the mutation. The C340T alteration was not observed in this sample indicating it is not a rare polymorphism (data not shown).

Patient CM S0429 showed an altered SSCP pattern in the exon containing the nucleotide region 2100-2259 
A.

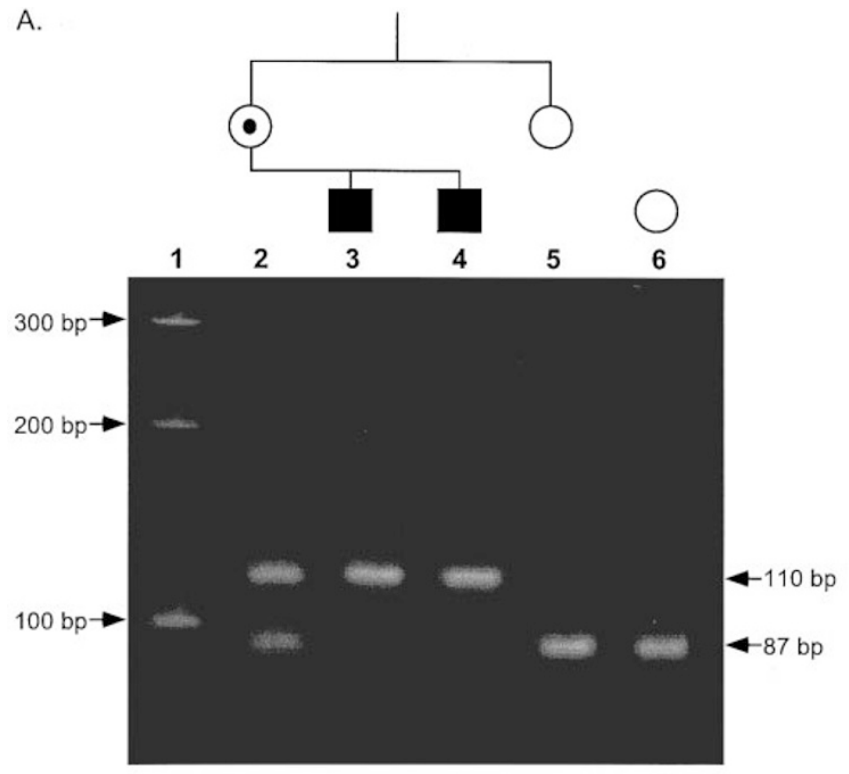

B.

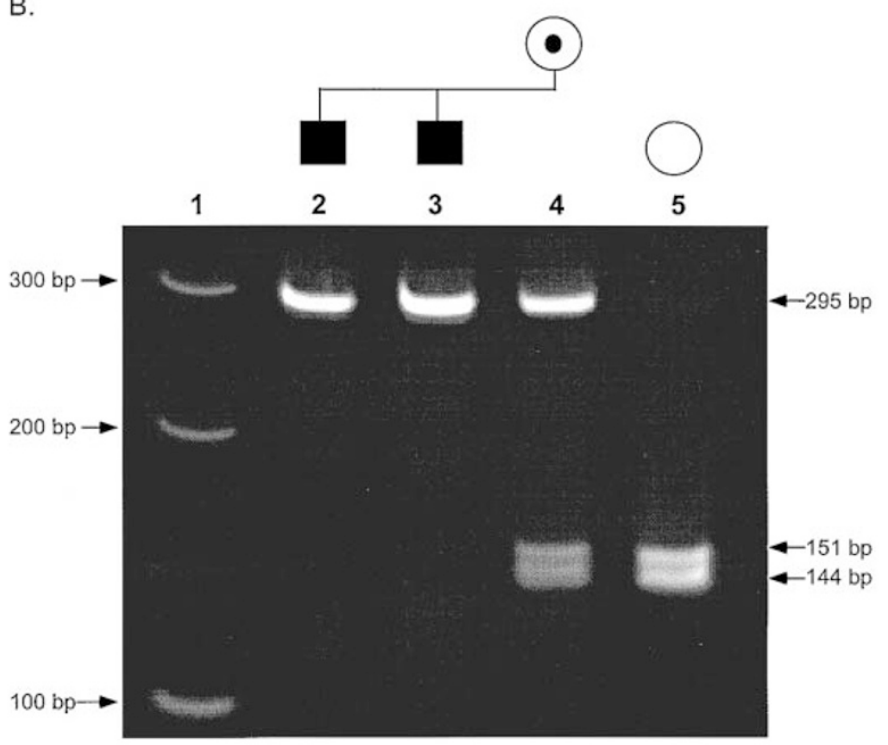

C.
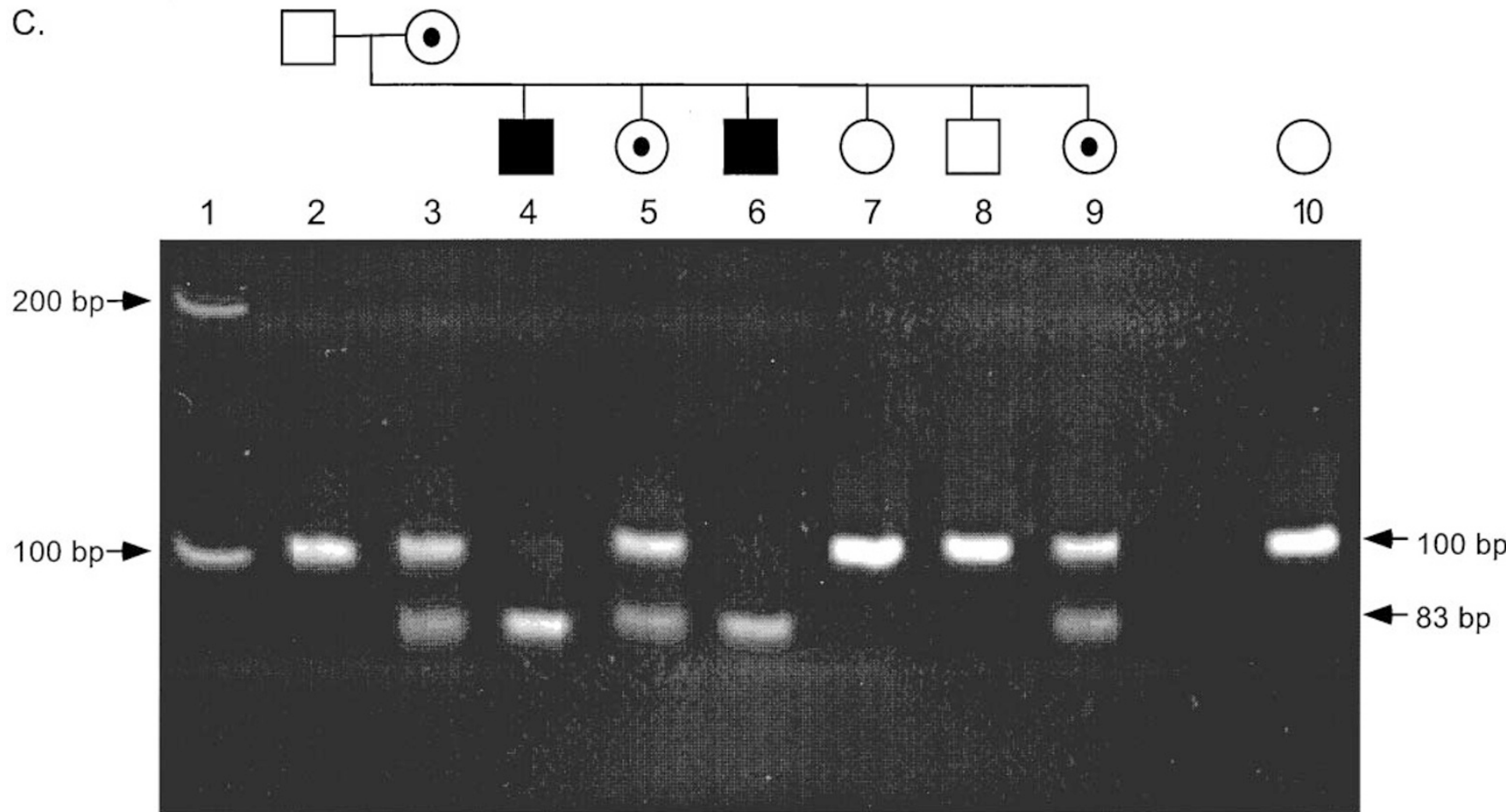

Figure 1 Segregation of mutations in R sk-2 in the three familial cases. a: Segregation of the C $340 \mathrm{~T}$ mutation in the family of proband 2598. The PCR product created using primers VH 236A and VH 237 was digested with $\mathrm{M} \mathrm{spl}$ and resolved on a $8 \%$ acrylamide gel. $L$ ane 1: 100 bp ladder (G IBCO BRL). L ane 2: M other. $L$ anes 3 and 4: The proband 2598 and his affected brother respectively. $L$ ane $5:$ A unt of the proband and his brother. $L$ ane6: Control individual. $\mathbf{b}$ : Segregation of the $G 2186 \mathrm{~A}$ mutation in the family of proband CM S0429. The PCR product created using primers WL 171 and W 191 was digested with M SpA 11 and resolved on a $8 \%$ acrlyamide gel. $L$ ane 1: 100 bp ladder. $L$ ane 2 and 3:T he proband CM S0429 and his affected brother respectively. $L$ ane 4: M other. $L$ ane 5: Control individual. c: Segregation of the C 2065T mutation in the family of proband 4534. The PCR product generated by using primers $E \times 21 F$ and WL 168 wsa digested with Sspl and resolved on a 8\% acrylamide gel. L ane 1: 100 bp ladder. L ane2: Father. L ane3: M other. $L$ anes 4 and 6: Proband 4534 and his affected brother respectively. $L$ anes 5 and 9: Sisters, who appear to be a carriers of the mutation. $L$ ane 7: Sister, who is normal. $L$ ane 8: Normal brother. $L$ ane 10: Control individual 
(Table 1). Sequence analysis of patient CMS0429 revealed a $G$ to $A$ ( $G 2186 A$ ), which caused a missense mutation ( $R 729 \mathrm{Q}$ ) (Table 2). This mutation resulted in the loss of an M spA 1 l site in the patient, which made it possible to test the mutation in the family and population. The affected brother and mother of the patient CM S0429 were tested and the G2186A alteration was shown to segregate with the disease (Figure $1 b)$. A nalysis of $100 \mathrm{X}$ chromosomes did not detect any $\mathrm{G} 2186 \mathrm{~A}$ mutation ruling out a rare polymorphism (data not shown).

Patient 4534 showed an abnormal SSCP pattern in the exon defined by nt 1960-2100 (Table 1). Sequence analysis of the patient showed that he was carrying a $C$ to $T$ (C2065T) mutation that gives rise to a premature stop codon (Q689X), and a truncated protein lacking the last 51 amino acids of the R sk-2 gene (Table 2 ). The C2065T mutation did not create or destroy any restriction sites, therefore a new primer Ex21F was designed (see $M$ aterial and $M$ ethods) which created an Sspl site in the patient. The family of the proband 4534 was tested for the C2065T mutation which was observed to segregate with the disease (Figure 1c). Two of the proband's sisters were found to be carriers of the mutant allele as a result of this test. Since this is an A frican-A merican family, $100 \mathrm{X}$ chromosomes from A frican-A merican individuals were tested for the alteration. The C2065T mutation was not detected in this set of chromosomes which indicated that it is not a rare polymorphism (data not shown).

The fifth patient (2423) exhibited an altered SSCP pattern in the exon containing the nucleotide region 407-486 (Table 1). Sequence analysis found a $2 \mathrm{bp}$ deletion (AG) of bases 451 and 452 (Table2). This deletion creates a significant frame shift and causes a premature termination $75 \mathrm{bp}$ downstream, thereby producing a severely truncated protein (Table 2). To test this deletion, PCR products from 100 normal chromosomes were separated on a $6 \%$ L ong R anger and $5.6 \mathrm{~m}$ U rea gel using the ALF DNA sequencer. Only the patient 2423 showed a shift of 2 bp (data not shown).

\section{Discussion}

Trivier et al ${ }^{6}$ identified the R sk-2 gene as the candidate gene for CLS based on mutational analysis. In all, these authors found six mutations. Four of these mutations two deletions, one insertion and one nonsense mutation - resulted in the truncation of the protein. The other two alterations were missense mutations involving

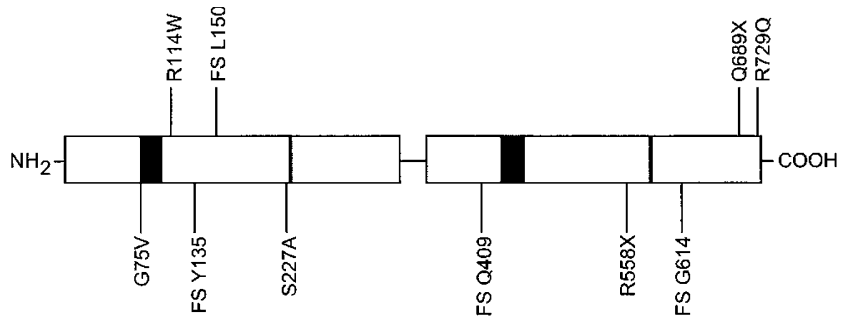

Figure 2 Schematic representation of the protein encoded by the R sk-2 gene showing the distribution of mutations. The open boxes represent the two non-identical kinase catalytic domains, containing the ATP binding sites (black boxes) and the APE sites (vertical line). M utations described in the present study are drawn above the schematic representation, and mutations reported previously are drawn below. Frameshift mutations are designated as FS, followed by the abbreviation and position of the amino acid at which the sequence begins to change

glycine and serine residues at positions 75 and 227 respectively (Figure 2). The glycine residue at position 75 is located within the highly conserved ATP-binding site, and the serine residue at position 227 is the putative phosphorylation site of the kinase domain. Thus both mutations likely affected the activity $\mathrm{N}$-terminal catalytic domain. Trivier et al ${ }^{6}$ were able to confirm this for the S227A mutation by showing a reduction in $\mathrm{S} 6$ kinase activity. This finding demonstrated that the CLS phenotype appeared to be linked to the loss of R sk-2 biological function.

The mutations found in the Rsk-2 gene in our five Coffin-L owry patients further confirms it as the gene associated wtih CLS. The C340T (R 114W) missense mutation was found in two unrelated patients of the same racial background (Table 2). A t present, this is the first instance of the same mutation occurring in more than one patient with CLS. The mutation is in a conserved region which is 12 amino acids downstream from the first A TP binding site of the $\mathrm{N}$-terminal kinase catalytic domain. Protein database comparison of this region showed that it is highly conserved in other organisms such as $\mathrm{X}$ enopus laevis, M us musculus, and Gallus gallus. ${ }^{13,14}$ Since the mutation replaces an arginine (positively charged) with a tryptophan (polar), there could be a conformational change in the protein due to the structure and charge of the substituted amino acid. This structural change may effect the binding of ATP, thereby reducing the autophosphorylation, which is predominantly mediated by the $\mathrm{N}$-terminal kinase catalytic domain. ${ }^{15}$ The other missense mutation ( $\mathrm{R} 729 \mathrm{Q}$ ), in patient CM S0429, involves the substitution of an uncharged glutamine residue for a basic arginine residue. As this arginine is highly 
conserved and occurs in a region suspected to interact with mitogen-activated protein kinases (M A PK s), ${ }^{16}$ it is very likely the alteration in charge adversely affects this interaction.

The remaining two mutations lead to a truncation of the R sk-2 protein. The nonsense mutation (Q 689X) in patient 4534 results in a premature stop codon (TA A) which eliminates the last 51 amino acids of the protein. The 2 bp deletion of bases 451 and 452 in patient 2423 causes a significant frameshift resulting in a TGA stop codon $75 \mathrm{bp}$ downstream (Table 2). This results in a truncated protein that lacks the major portion of the $\mathrm{N}$-terminal kinase domain and the entire $\mathrm{C}$-terminal kinase domain.

Of the 10 mutations found by us and Trivier et al, ${ }^{6}$ six result in the creation of a truncation of the Rsk-2 protein. A Ithough these numbers are small, the results indicate that the protein truncation test (PTT) may be useful for mutation detection for $\mathrm{CLS} .^{17}$

The C-terminal kinase domain of Rsk-2 interacts with MAPK s, which has been shown to phosphorylate and further stimulate the autophosphorylation of the R sk-2 C-terminal domain. Once the C-terminal kinase domain is phosphorylated, it is able to phosphorylate and activate the $\mathrm{N}$-terminal kinase domain. Therefore both the kinase domains are required for the maximal activity of the protein. ${ }^{15}$ The patient with the 451delA G deletion, which truncates the protein in the $\mathrm{N}$-terminal kinase catalytic domain, has a more severe phenotype than the patient with Q689X, the nonsense mutation which truncates the protein at the C-terminal end (Figure 2). This patient has been non-ambulatory since the age of 11 , a rare occurrence in CLS patients. This would indicate that loss of function of both kinase domains is more detrimental than the loss of the C-terminal kinase activity as expected based on our knowledge of members of the RSK family. ${ }^{15}$ Similar phenotype-genotype correlations will now be possible for other CLS patients and may address the variable degree of mental retardation which exists in CLS patients. $^{6}$

\section{Acknowledgements}

We thank D an R iconda, MS and D rs D avid Flannery, Cindy Powell, R ichard Schroer and L aurie Seaver for contributing the patients. D r B ernhard $\mathrm{H}$ ane assisted in running the SSCP analysis and the sequencing gels on the $A L F$. This work was supported, in part, by grants from N ICHD (2R O IH D 26202) and The Fullerton Foundation (97-4) to CES, and a grant from the South Carolina Department of Disabilities and
Special Needs (SCDDSN). We also thank the Commission of the $E$ uropean Communities and the A ssociation Française contre les M yopathies for their support. CL was supported by the Furman A dvantage Internship Program.

\section{References}

1 Temtamy SA, Miller JD, H ussels-Maumenee I: The Coffin-L owry syndrome: an inherited facio-digital mental retardation syndrome. J Pediatr 1975; 86: 724-731.

2 Young ID: The Coffin-Lowry syndrome. J Med Genet 1988; 25: 344-348.

$3 \mathrm{H}$ anauer A, A lembik Y, Gilgenkrantz S et al: Probable localization of the Coffin-L owry locus in X p22.2-p22.1 by multipoint linkage analysis. A m J M ed Genet 1988; 30: 523-530.

4 Biancalana V, Trivier $E$, Weber $C$ et al: Construction of a high-resolution linkage map for X p22.1-p22.2 and refinement of the genetic localization of the Coffin-Lowry syndrome gene. G enomics 1994; 22: 617-625.

5 Bird H, Collins A L, O ley C, L indsay S: C rossover analysis in a British family suggests that Coffin-L owry syndrome maps to a 3.4-cM interval in X p22. A m J M ed G enet 1995; 59: 512-516.

6 Trivier E, De Cesare D, Jacquot S et al: M utations in the kinase R sk-2 associated with Coffin-Lowry syndrome. Nature 1996; 384: 567-570.

7 Moller DE, Xia CH, Tang W, Z hu AX, Jakubowski M: Human rsk isoforms: cloning and characterization of tissue-specific expression. Am J Physiol 1994; 266: C 351-C 359

8 Bjorbaek C, Vik TA, Echwald SM et al: Cloning of a human insulin-stimulated protein kinase (ISPK-1) gene and analysis of coding regions and mRNA levels of the ISPK -1 and the protein phosphatase- 1 genes in muscle from NIDDM patients. D iabetes 1995; 44: 90-97.

9 Erickson E, M aller J L: Substrate specificity of ribosomal protein $\mathrm{S} 6$ kinase II from $X$ enopus eggs. Second M essengers Phosphoproteins 1988; 12: 135-143.

10 Schwartz CE, U Imer J, B rown A, Pancoast I, Goodman $\mathrm{HO}$, Stevenson RE: A llan-H erndron syndrome II. Linkage to DNA markers in X q21. A m J Hum G enet 1990; 47: 454-458.

11 Gurrieri F, Prinos P, Tackels D et al: A split hand-foot (SH FM 3) gene is located at 10q24-q25. A m J Med G enet 1996; 62: 427-436.

12 Haliassos A, Chomel JC, Tesson L et al: Detection of minority point mutations by modified PCR technique: a new approach for a sensitive diagnosis of tumor-progression markers. Nucleic A cid Res 1989; 17: 8093-8099.

13 Jones SW, E rickson E, B lenis J, M aller J L, E rickson R L : A $X$ enopus ribosomal protein $\mathrm{S} 6$ kinase has two apparent kinase domains that are each similar to distinct protein kinases. Proc Natl A cad Sci USA 1988; 85: 3377-3381.

14 A Icorta DA, Crews C M, Sweet LJ, Bankston L, Jones SW, Erickson RL: Sequence and expression of chicken and mouse rsk: homologs of $\mathrm{X}$ enopus laevis ribosomal $\mathrm{S} 6$ kinase. Mol Cell Biol 1989; 9: 3850-3859. 
15 Fisher $T L, B$ lenis $\mathrm{J}$ : Evidence of two catalytically active kinase domains in pp90 $^{\text {rsk }}$. Mol Cell Biol 1996; 16: 1212-1219.

16 Zhao Y, Bjorbaek C, M oller DE : R egulation and interaction of pp90(rsk) isoforms with mitogen activated protein kinases. J Biol Chem 1996; 271: 29773-29779.
17 R oest PA M, R oberts R G, Sugino $S$, van $O$ mmen $G-J B$, den $D$ unnen JT: Protein truncation test (PTT) for rapid detection of translation-terminating mutations. $\mathrm{H}$ um $\mathrm{M}$ ol G enet 1993; 2: 1719-1721. 